\title{
Childhood obesity: enough discussion, time for action
}

\author{
COLIN MICHIE
}

Childhood obesity is becoming more common and rates of obesity have not responded to attempts over the last 10 years to reduce them. Not only is there a failure to stem the tide of new cases, we have not performed well in the care of those already suffering with obesity, with communities and health care services lacking systems and resources to manage the complications that arise in obese children and young people.

In February 2013, the Royal College of Paediatrics and Child Health, on behalf of the Academy of Medical Royal Colleges, launched 'Measuring up' - a report which saw UK doctors and academics deliver a series of recommendations aimed at addressing the UK's obesity problem.

Three years have now passed and, given that no significant inroads have been made, it is clear that without heavy investment in obesity prevention, we will have to move from talking about a 'ticking time bomb' to picking up shrapnel.

Why do we need to worry about high obesity rates? Currently nearly a quarter of children under five and a third by the age of 10 are overweight or obese. This puts them at a high risk of developing complications including hypertension, musculoskeletal problems, type 2 diabetes and mental health difficulties. As obesity is developing in younger children, these manifest earlier. In the last decade hospitals in England and Wales reported a four-fold increase in the number of children and teenagers presenting with these diagnoses. Diabetes - to examine just one complication - is a rapidly growing noncommunicable disease that is challenging healthcare services across the globe.

A paper published in the WJP World Journal of Paediatrics recorded children as young as eight with type two diabetes, therefore treatment is going to be required for longer periods of time. The same journal reported that obese parents are more likely to have an obese child; with an obese child being $80 \%$ more likely to continue on that trajectory, with its negative health outcomes, as they move through life. This programming generates a spiral of

Royal College of Paediatrics and Child Health's Nutrition Committee, UK.

Address for correspondence: Dr Colin Michie

Former Chair of the Nutrition Committee, Royal College of Paediatrics and Child Health, Ealing Hospital, LNWHT, London, UB1 3HW, UK.

E-mail: lauren.snaith@rcpch.ac.uk

Br J Diabetes 2016;16:4-5

http://dx.doi.org/10.15277/bjd.2016.055 complications through society. For example, as obesity in youth strongly influences quality of life, ability to work, long term mental health and national productivity, it has been observed recently that just under $30 \%$ of young people in the USA are too heavy to qualify for military service.

It has become clear from attempts to help children with their food intakes that family environments are crucial. Governed by parents and subjected to many modern media strategies, children's diets, portion sizes, patterns of eating and physical activity are family driven, particularly in the early years. Families provide biological and learned preferences in terms of diet, as illustrated by the finding that overweight or obese parents do not recognise the same problem of weight in their own children.

\section{A twinkle of light}

Whilst 2016 still holds much concern when it comes to obesity, it does also bring a twinkle of light in the form of Government's childhood obesity strategy - something that was welcomed by the Royal College of Paediatrics and Child Health when it was announced last May. As a paediatrician I, like many others, wait in hope that this strategy has a series of effective measures that will tackle this public health problem once and for all.

Obesity - a financial burden in times of limited resource The country's high obesity rate makes the UK the heavyweight of Western Europe. We spend more treating the health and social costs associated with obesity - an estimated $f 47 \mathrm{bn}$ a year - than we do on fighting the war against terror. The WJP World Journal of Paediatrics reported that healthcare and medicine expenses of obese adults were $36 \%$ and $77 \%$ (respectively) higher than those who were not obese. Evolution of this expense has not been planned - a McKinsey report in 2014 (Overcoming obesity: an initial economic analysis) noted that although $\mathrm{f} 10$ billion is spent annually in the UK on treating diabetes, only $£ 638$ million is spent preventing it.

If we rewind back to February 2013, the Academy of Royal Medical Colleges report ('Measuring up') made a series of recommendations, some of which have since been implemented. These included food labelling and targeted education and training for health professionals. Others still remain to be implemented $-\mathrm{a}$ ban on junk food advertising before $9 \mathrm{pm}$, a sugary drinks tax and a commitment to create a healthier food environment in schools. Several of the preventative options have been modelled and found to be more effective than clinical interventions. For instance, taxation of sugary drinks would not only generate tax revenue but averts disability adjusted life years and increases quality adjusted 
life years. Prevention is likely to provide the best value for healthcare pounds.

\section{Making the healthy choice the more affordable choice: the challenges}

Poverty impacts obesity. For children aged between four and five years, obesity rates varied from $5.5 \%$ in the Royal Borough of Windsor and Maidenhead to $14.4 \%$ in the London borough of Hackney. In year six it ranged from $11.1 \%$ in the affluent borough of Richmond upon Thames to a startling $26.7 \%$ in the economically deprived borough of Southwark.

At a time where healthy fresh food is often more expensive than fast food and many multi-buy options in supermarkets are targeted at unhealthy products such as sweets, crisps and fizzy drinks, it's no wonder that families, especially those on low incomes, are buying unhealthy food.

A WHO report (2015 Interim report of the Commission on ending Childhood Obesity, Geneva) has recognised that because of the global nature of food companies, international collaborations and interventions are required. It was encouraging to see Tesco report that it had removed 2 billion calories from its juices and 600 million calories from several ranges of products during an All Party Parliamentary Group last year.

If we are to get to grips with the obesity crisis, initiatives are required to make the healthy choice a more affordable choice for everyone. One measure would be to mandate comprehensive labelling of processed food and provide better information in restaurants and take-aways relating to calories and food composition for portions served.

But it isn't just fast and cheap unhealthy food at fault.

Soft drinks are the largest source of sugar for children, causing obesity and tooth decay. NHS figures show that 25,800 children aged between five and nine are admitted to hospital with tooth decay every single year - this has rocketed by $14 \%$ in just three years. It is therefore logical to tax this food ingredient first - a move backed by the UK's Chief Medical Officer, the London Food Board, the British Dental Association and the London Health Commission. Many in the voluntary sector such as the Children's Food Campaign and Citizens UK are also campaigning for this move. In New York, Mexico, Hungary and France a tax on high-sugar carbonated soft drinks has been introduced and early Mexican data show a reduction in their consumption as a consequence.

As well as cheap promotional offers on fast food and fizzy drinks, children and families are bombarded with clever advertising campaigns that familiarise them as consumers with particular brands, generating associations of these products with convenience and value for money.

On an average day, children walk past a numerous billboards or bus stops advertising fast food, and when they get home and switch on the television, work or game online, it's likely they'll see an advert promoting fast food. But it doesn't stop there. For families visiting festivals, concerts or sporting events, they will be exposed to a barrage of promotional material advertising fast food, fizzy drinks or alcohol. These all contribute to the familiarity of unhealthy living and make healthy choices more difficult.

Making the healthy choice the more affordable choice: collective and targeted actions

Collective and coordinated action is required from many groups including families, healthcare professionals, schools, the advertising industry, food industries and the government. But as with many changes, there is considerable benefit to be derived with a focus on prevention and early intervention. In the UK this approach may be responsible for the slowing of the rates of obesity in the youngest group of children captured in the National Child Measurement Programme.

Crucially working with women before pregnancy can ensure they have a healthy weight before conception even takes place: it may be possible to prevent early programming of their children. By doing this we would also reduce the likelihood of women developing conditions such as gestational diabetes, hypertension and preeclampsia. The foetuses of pregnant women who are overweight or obese are at increased risk of prematurity, stillbirth and congenital anomalies. Last year, the Chief Medical Officer for England highlighted obesity as a significant risk to women's health in the UK.

Intervention in the classroom can ensure that children are brought up from a young age understanding what it means to lead a healthy lifestyle. We need to teach them what constitutes a healthy meal, an appropriate portion size, how to shop, then prepare a meal and how physical activity complements healthy eating. As a College we have long called for compulsory cooking lessons in all schools coupled with a commitment to create healthy food environments in schools, child-care settings, and hospitals. We are keen to see Government build on the Change 4 Life campaign and commit to a further public education campaign on healthy nutrition and healthy lifestyles.

NHS Chief Executive Simon Stevens in his Five Year Forward View has put preventing ill health as the top priority, emphasising its importance further. Recommendations for interventions, mandatory and otherwise, have also been outlined in a proposed National Obesity Framework (2016) prepared by an All Party Parliamentary Group.

In addition, success at tackling childhood obesity will also require good data collection and monitoring - the launch of the National Institute for Health Research's 'Big challenge' will help support this element.

Without urgent collective action, the UK's obesity problem will be difficult to control. If obesity rates rise further, complications in pregnant women, younger children as well as adolescents will escalate. The country's health service will be placed under immense pressure to treat these conditions, limiting choices of moving forward with other types of care. Of course we can undertake the fire-fighting to help those already struggling with their weight. However emphasis, investment and collaboration are required for prevention.

Conflict of interest Colin Michie has no conflicts of interest to declare. Funding Colin Michie is not in receipt of funding or income related to the subject matter of this script 